\title{
Did Self-Directed Learning Curriculum Guidelines Change Taiwanese High-School Students' Self-Directed Learning Readiness?
}

\author{
Chang-Hua Chen ${ }^{1} \cdot$ Ken-Zen Chen $^{2}$ (1) $\cdot$ Hsiao-Feng Tsai ${ }^{1}$
}

Accepted: 12 April 2021/Published online: 6 May 2021

(C) De La Salle University 2021

\begin{abstract}
With the rapid changes in globalization and technology advancement, self-directed learning is argued repeatedly as a key competency needed to survive in the twenty-first century. In August 2019, the Taiwan Ministry of Education implemented the new Curriculum Guidelines for 12-Year Basic Education. Being Taiwan's first official curriculum that promoted self-directed learning, this study contributed to the emerging knowledge of how the introduction of the curriculum guidelines affected students' readiness for self-directed learning. Three cohorts of high school students from seven schools returned 10,020 valid surveys. The Self-Directed Learning Readiness Scale (SDLRS), a reputable instrument developed by Lucy Guglielmino (2000), was used in the study. The results provided a bird's-eye view of evidence supporting our explanations for the positive, though slight, effect of implementing new curriculum guidelines in fostering selfdirected high-school learners. Moreover, the progression of self-directed learning readiness appeared differently among schools and among different demographic associations. We suggest that future researchers both (a) qualitatively
\end{abstract}

Supplementary Information The online version contains supplementary material available at https://doi.org/10.1007/s40299-021-00582-w.

Ken-Zen Chen

kenzenchen@nctu.edu.tw

Chang-Hua Chen

cchen72@mail.naer.edu.tw

Hsiao-Feng Tsai

indigo@naer.edu.tw

1 National Academy for Educational Research, New Taipei City, Taiwan

2 National Chiao-Tung University, Hsinchu City, Taiwan explore how specific latent variables were changed in different instructional interventions, and (b) conduct panel studies to advance our understanding of curriculum reform and learners' self-direction.

Keywords Self-directed Learning ·

Curriculum Guidelines · High-School Students

\section{Introduction}

\section{Background}

Self-directed learning is effective (Butler \& Winne, 1995). With the rapid changes in globalization and technological advancement, self-directed learning (SDL) is argued repeatedly to be a key competency to survive in the twentyfirst century (Cynthia, 2015). Countries have reformed educational agenda to prepare future citizens as self-directed learners who question, reflect, persevere, and take responsibility for their own learning. Curriculum for Excellence (CfE), a national curriculum for Scottish schools implemented in 2010, identified four key competencies for young people to develop if they are to become (a) successful learners, (b) confident individuals, (c) responsible citizens, and (d) effective contributors. According to the Framework for 21st Century Competencies and Student Outcomes, Singapore wants students from its education system to possess a strong sense of self-awareness, a sound moral compass, and the necessary skills and knowledge to assume future challenges. In its Learning Framework 2030, the Organization for Economic Co-operation and Development [OECD] (2018) envisioned a future society of well-being for all individuals, communities, and the world, by enabling supportive educational 
systems that develop future global citizens. During the worldwide schools' closures due to the COVID-19 outbreak, self-directed learning again was cited by global education leaders as one of the key educational responses to the pandemic (Reimers \& Schleicher, 2020).

Similarly, the Taiwan Ministry of Education (MOE) implemented the new Curriculum Guidelines (nCG) for 12-Year Basic Education, starting in the 2019 school year. To achieve the Guidelines' foundational educational beliefs, that is, taking initiative, engaging in interaction, and seeking the common good (National Academy for Educational Research, 2018), self-directed learning is listed as one of the key competencies and approaches to cultivating spontaneous and motivated learners. Emphasizing SDL 16 times in the Guidelines is the first time that MOE clearly instructed schools to promote SDL to "ensure that students can conduct learning in an adequate and selfdirected manner" (p. 34). The nCG encouraged self-directed learning programs be incorporated into school-based curriculum (pp.11, 13) and alternative learning periods (pp. 21, 28). Moreover, these are the first Guidelines asking schools 'to improve students' learning outcomes and develop their capability in self-directed and lifelong learning", and further asks teachers to "guide students in using various... motivational strategies; general learning strategies; domain-, cluster-, program-, and subject-specific learning strategies; thinking strategies; and metacognitive strategies". (p. 48).In addition, nCG covers a wide array of readiness for SDL in its excerpts (see Appendix A for the list of cross-references). Although there were no prior large-scale studies exploring Taiwanese high-school students' SDL, we reasoned that the initiation of the nCG may lead to positive changes in school practices that reinforce the teaching of self-directed learning, improving students' readiness for SDL, and, subsequently, positively affecting students' learning performances. We proposed that schools that implement some manner of SDL instructions based on nCG would empower students to engage in SDL.

\section{Research Questions and Hypotheses}

Under the context of the curriculum reforms in Taiwan, several gaps exist in the current understanding of self-directed learning readiness (SDLR) that warrant further investigation. We investigated the following questions and hypotheses:

Research Question 1: What were the current status of the Taiwanese high school students' SDLR?

RQ1-1: How well have these high-school students performed in the SDLR?

RQ1-2: Can SDLR differences be found among demographic variables?
H1 No demographic differences are found among the students.

RQ1-3: Can implementation of the nCG improve SDLR?

H2 No SDLR score differences are found among control groups within three cohorts.

Research Question 2: How do SDL piloting programs improve students' SDLR?

RQ2-1: Can SDL piloting programs in high schools improve SDLR?

H3 No SDLR score differences are found among experimental groups within three cohorts.

H4 No SDLR score differences are found between control and experimental groups within three cohorts.

RQ2-2: Do those SDL piloting programs reveal particular advantages in regard to these SDLR latent variables? In what subdomains did they improve?

H5 No SDLR score differences are found among piloting programs.

\section{Related Work}

SDL is not new. Bandura's (1977) early work about social cognitive theory defined SDLs as individuals who monitor, evaluate, and then learn from the cognition, motivation, affection, and behavior of themselves. Bandura (1986) further identified three processes in SDL: self-observation, self-judgements, and self-reactions. SDL is not about learning itself; instead, it is a meta-theory about learninghow-to-learn (Steffens, 2015). Self-direction is both an attitude and an ability (Dickinson, 1995): As an attitude, learners remain positive, independent, interested, strategic, and goal-oriented; as an ability, they take ownership and responsibility for their decisions and learning results. Learning self-regulation assumes four basic characteristics in learners (Pintrich, 2004): (a) the learner actively constructs acquired knowledge, (b) the learner can monitor and adjust his or her own learning, (c) the learner achieves selfdetermined goals or standards, and (d) the learner connects individuals, contexts, and performances. Studies in K-12 education may put focus on self-regulation, including establishing proximal goals (Zimmerman et al., 2015) generating strategic action plans (Zimmerman et al., 2017), and reflecting lessons learned from the experience of learning (Lodico et al., 1983). These self-regulated behaviors facilitated both SDL and future learning transfer (Hacker et al., 1998). 
The current literature offers extensive accounts of SDL and individual differences based on characteristics such as attribution (Schunk, 2016), self-efficacy and skill (Schunk \& Rice, 1987), self-control and goal-setting (Schunk \& Rice, 1989, 1991), self-determination (Deci \& Ryan, 2000), intrinsic motivation (Corno, 2001), attitude toward growth (Dweck, 2006), and self-awareness (Vallerand et al., 1997); or based on teachers' providing supportive learning environments (Camahalan, 2006; Turner et al., 2002), paving proper learning roadmaps (Bandura, 1986; Schunk et al., 2008), aligning tasks to learners' zone of proximal development (Wiliam, 2018), formative assessment (Panadero et al., 2018), and providing training on learning strategies (Fiorella \& Mayer, 2015; Lodico, et al., 1983;). This prior work provides a basis for deeper investigations of SDL in detailed classroom learning environments. Recent SDL studies extend foci on pivotal trends of learning, such as Mass Open Online Courses (MOOCs, Alonso-Mencía et al., 2020; Zhu et al., 2020), home-based learning in reaction to the COVID-19 outbreaks (e.g., Chen, 2020; Mahlaba, 2020), and twenty-first century skills (Karatas \& Zeybek, 2020). Scholarly works also have provided linkage between SDL and educational reforms worldwide. These works may look into the linkage from a historical vein, technology-enriched learning platform, or change of student attitude. In east Asia, Taiwan's thirdwave educational reform that emphasizes students engaging in SDL, had a root in learning deregulation since 1990s (Pan \& Nyeu, 2019); Singapore leveraged its Student Learning Space (SLS) to enable home-based learning as an reaction to COVID-19 outbreak (Hung et al., 2020); although the reform of Hong Kong's New Senior Secondary (NSS) school curriculum promotes SDL, a student survey revealed less optimistic responses in engaging the curriculum (Hui et al., 2020). Those lines of research show that, even if implementing fully self-directed learning in institutional contexts is nearly impossible, every learning situation in schools offers the potential for learners to develop the skills and attitudes supportive of SDLR (Guglielmino, 2013, p. 2): These are characteristics that are "desirable, necessary, or essential for self-direction in learning" (Guglielmino, 1989, p.236). Literature also supports the notion that SDLR is a developable capacity (e.g., Amey, 2008; Daniels, 2011; Dynan et al., 2008; Kasworm, 1983; Litzinger et al., 2005; Nordin et al., 2016; Posner, 1991; Slaughter, 2009).

Despite students being the major recipients of educational reforms, the understanding of students' readiness to engage in self-directed learning under reforms seems sparse. Moreover, while controlled laboratory experiments hold much promise for empirically validating the effectiveness of SDLR, such an approach is not without challenges. First, learning is a generative activity (Fiorella \&
Mayer, 2015), where development of self-direction and self-regulation take time (Paris et al., 2001). Second, learning autonomy is rooted in contexts (Benson, 2001). Third, self-determination plays a vital role in SDLR, where students are empowered to follow what motivates them to learn in the real world (Deci et al., 1991). To circumvent such difficulties, this research committed to developing an alternative research strategy to generate insights that offer a potentially richer understanding of SDLR under the implementation of nCG.

\section{Research Design}

To contribute to the unique understanding of SDLR by answering the mentioned two research questions, a quasiexperimental design was conducted. Seven high schools that had prolonged participation in instructional research with our Academy were recruited. Four of them had developed school-based SDL pilot programs a year prior to the official launch of nCG. We collected three cohorts of data in September 2018 (nothing was implemented), May 2019 (nCG-guided SDL pilot programs that had been functioning for about a year, while other classes conducted teaching as usual), and January 2020 (nCG was implemented fully so that all classes were receiving nCG-guided SDL experiences). Figure 1 shows the sampling frame and research design of the study. With this design, we assumed that group 1C and 1E in Cohort 1 shared the same starting point in SDLR. After a year of implementation of SDL pilots, the experimental group (2E) should have outperformed its counterparts (2C, business-as-usual) and was expected to have made some progress (1E) in SDLR. Meanwhile, we should observe higher SDLR for all students after nCG was implemented fully (i.e., Cohort 3 performed better than Cohorts 1 and 2). Finally, after the full implementation, the business-as-usual cohort (3C) should have performed equally or slightly less than the pilots (3E), given that students in the pilot programs had one-year more of exposure under nCG.

\section{Instrumentation and Survey Procedure}

The Self-Directed Learning Readiness Scale (SDLRS) is a 58-item, 5-point Likert-type scale that produces one score to measure the extent of an individual's SDLR. It is referred to as the Learning Preference Assessment when administered to avoid response bias. The instrument measures eight latent variables of readiness: (1) TR: Tolerance of risk, ambiguity, and complexity in learning; (2) SC: Self-concept as an effective independent learner; (3) IL: Initiative in learning; (4) AR: Acceptance of responsibility for one's own learning; (5) LL: Love of learning; (6) CT: Creativity; (7) VL: View of learning as a lifelong, 


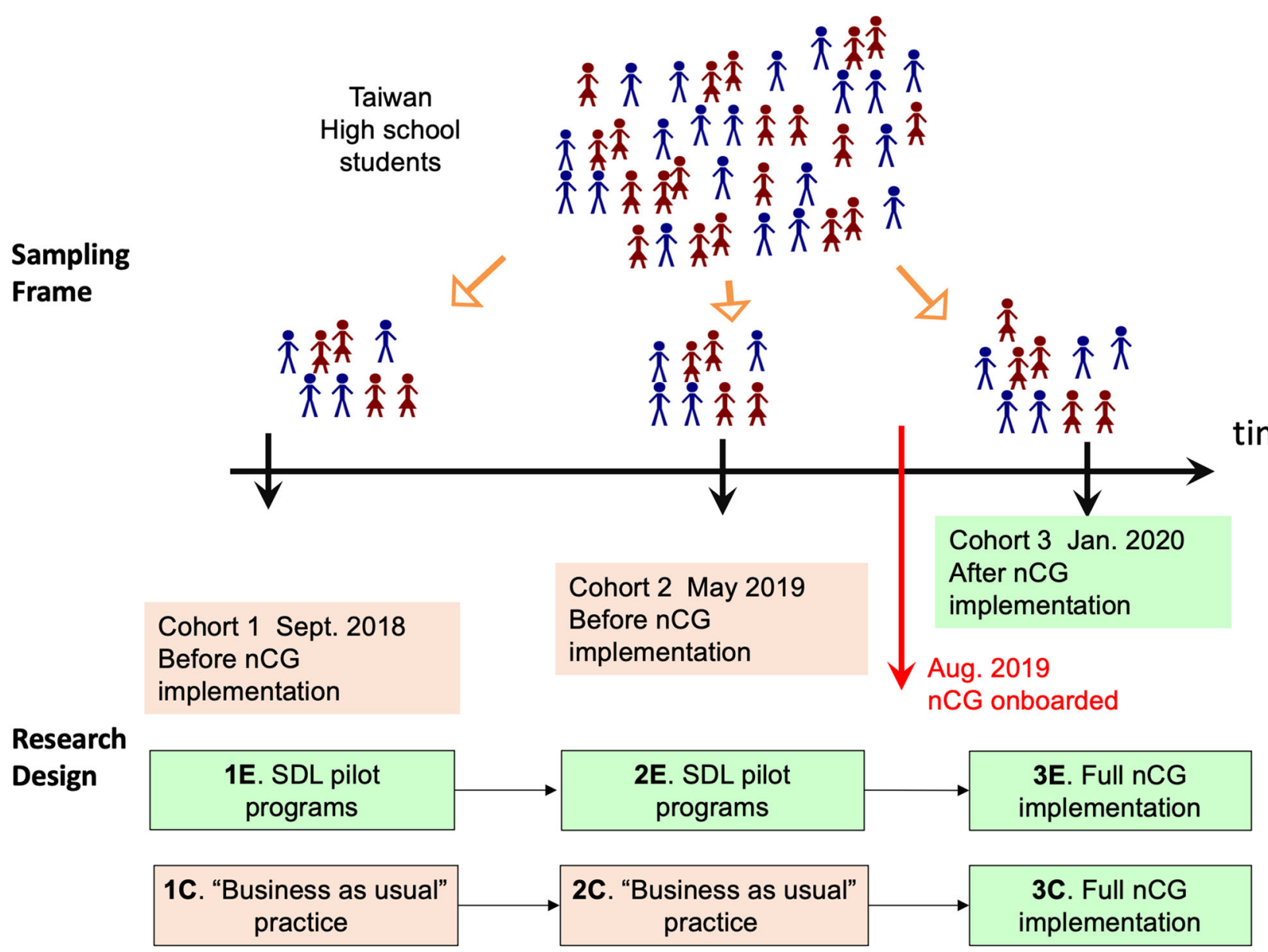

Fig. 1 Sampling frame and research design

beneficial process; and (8) SU: Self-understanding, reflection on one's own learning. The SDLRS has been long established as a high validity and reliability scale; research using this instrument has been conducted in more than 50 countries in 23 languages (Guglielmino \& Associates, 2010). Studies have demonstrated internal consistency levels with test-retest reliability of 0.829 and 0.79 , Pearson split-half reliability estimate of 0.94 , and Cronbach alpha reliability coefficient of 0.87 (Guglielmino \& Guglielmino, 1991). In addition to internal reliability estimates, Finestone (1984) and Wiley (1981) reported test-retest reliability coefficients of 0.82 and 0.79 . After consulting with the author of SDLRS, we obtained her agreement in translating and using SDLRS in Taiwan. Prior to the present study, we concluded fitness of the SDLRS factorial structure in Taiwan's high-school students in an earlier confirmatory factor analysis (Chen et al., 2020), reported sound validity and reliability (Cronbach's alpha $=0.94$ ). SDLRS were administered in seven high schools; paper and online formats were both used wherever convenient. During the survey, students were asked to read a research statement, sign an informed consent, and then indicate the degree to which that statement accurately described their own attitudes of learning. Each student completed the SDLRS and also provided information on gender and grade. It took less than $30 \mathrm{~min}$ for high-school students to complete the survey at the schools.

\section{Participation Profile}

Following the direction of the SDLRS author, cases that were completely empty or missed six or more items were removed from analysis. The valid samples included 3,694, 2,892, and 3,434 students for the three cohorts, respectively (Fig. 1). Among remaining valid cases, missing values were imputed with 3 (the middle value). Table 1 shows the sample distributions.

\section{Data Analysis}

The data analysis was conducted as follows to answer the addressed research questions. First, a descriptive analysis of all items was performed for the full sample. For the following statistical tests, we defined the significance level, 
Table 1 Sample distribution

\begin{tabular}{|c|c|c|c|}
\hline & Sept. 2018 (Cohort 1) & May 2019 (Cohort 2) & Jan. 2020 (Cohort 3) \\
\hline \multicolumn{4}{|c|}{ Experimental Assignment } \\
\hline Experiment & 1E: SDL Pilot Programs & 2E: SDL Pilot Programs & 3E: Full nCG implementation \\
\hline Control & 1C: Business-as-usual & 2C: Business-as-usual & 3C: Full nCG implementation \\
\hline \multicolumn{4}{|l|}{ Variable } \\
\hline Descriptor & $n(\%)$ & $n(\%)$ & $n(\%)$ \\
\hline \multicolumn{4}{|l|}{ Gender } \\
\hline Male & $1,704(46.1)$ & $1,352(46.7)$ & $1,703(49.6)$ \\
\hline Female & $1,839(49.8)$ & $1,481(51.2)$ & $1,681(49.0)$ \\
\hline Unanswered & $151(3.9)$ & $59(2.0)$ & $50(1.4)$ \\
\hline \multicolumn{4}{|l|}{ Level } \\
\hline Senior high & $969(26.2)$ & $505(17.5)$ & $445(13.0)$ \\
\hline Junior high & $2,725(26.2)$ & $2,387(82.5)$ & 2,989 (87.0) \\
\hline \multicolumn{4}{|l|}{ School } \\
\hline A & 478 (12.9) & $433(15.0)$ & $689(20.1)$ \\
\hline B & $454(12.3)$ & $164(5.7)$ & 408 (11.9) \\
\hline $\mathrm{C}$ & $822(22.3)$ & $819(28.3)$ & $856(24.9)$ \\
\hline $\mathrm{D}$ & $77(2.1)$ & $73(2.5)$ & $133(3.9)$ \\
\hline $\mathrm{E}$ & $95(2.6)$ & $39(1.3)$ & $87(2.5)$ \\
\hline $\mathrm{F}$ & $1,114(30.2)$ & $713(24.7)$ & $625(18.2)$ \\
\hline G & $654(17.7)$ & $651(22.5)$ & $636(18.5)$ \\
\hline Total & $3,694(100.0)$ & $2,892(100.0)$ & $3,434(100.0)$ \\
\hline
\end{tabular}

Cohort 1 Before implementation of nCG; Cohort 2 before implementation of nCG while a few SDL piloting programs were implemented for a school year; Cohort 3 Full implementation of $\mathrm{nCG}$

Urban schools A, C, D, and G; Rural schools B, E, and F; Location Northern (A, B, C, and D), Southern (G), Eastern (E and F); Controls A, B, E, and G; Experiments (Pilots) A, C, D, and F

denoted by $\alpha$ (i.e., Type I error), at 0.01 . To answer RQ1-1, clustering analysis was used to identify distinct groups in high-school students. To test whether demographic variables predict changes of scores (RQ1-2/H1), stepwise multiple regressions were used. Once again, to verify whether/which piloting programs and nCG improve SDLR, and in what SDL latent variables were they improved, hypothesis tests for means (e.g., $t$-test, ANOVA, and post hoc analyses) were conducted respectively (RQ1-3/H2 and RQ2-1/H3 and H4). Finally, hypothesis tests for means were also used to understand different SDLR performances among piloting programs (RQ2-2/H5).

\section{Results}

\section{RQ1-1: How well have these students performed in SDLR?}

Table 2 describes Taiwanese high-school students' SDLR scores before and after nCG implementation. Possible SDLRS scores range from 58 to 290, with an average U.S. adult score of $214(S D=25.59)$. Moreover, the author of
SDLRS further interpreted scores as 58 to 201 (belowaverage readiness), 202 to 226 (average readiness), and 227 to 290 (above-average readiness). Comparatively, the students participating in this study had below-average SDLR scores among the three cohorts $(M=195.9,197.3$, and 198.9).

To better understand SDLR patterns among the participating students, cluster analysis was applied. Clustering analysis is one of the unsupervised discoveries of datamining techniques that explores and visualizes patterns by grouping observations that share similar attributes. Given we did not have assumptions about the structure of the data (i.e., types of Taiwanese high-school self-directed learners), a $k$-means an algorithm with tenfold cross-validation was used to cluster students based on their shared characteristics in SDLR. Based on the within-cluster sum of squared errors (the "elbow" appears at $k=4$ or 9 ; see Fig. 2), an optimal four-cluster model was selected, which revealed the following patterns: (1) the well-developed self-directed learners under nCG, (2) students who had average SDLR among all three cohorts, and (3 and 4) the lower-performing, self-directed learners. Appendix B includes the results of the clustering analysis. 
Table 2 Descriptive statistics of SDLRS score

\begin{tabular}{|c|c|c|c|c|c|c|c|}
\hline \multirow[t]{2}{*}{ Var } & \multirow[t]{2}{*}{ Descriptor } & \multicolumn{2}{|c|}{ Sept. 2018 (Cohort 1) } & \multicolumn{2}{|c|}{ May 2019 (Cohort 2) } & \multicolumn{2}{|c|}{ Jan. 2020 (Cohort 3) } \\
\hline & & $n(\%)$ & Mean Score $(M, S D)$ & $n(\%)$ & Mean Score $(M, S D)$ & $n(\%)$ & Mean Score $(M, S D)$ \\
\hline \multirow[t]{2}{*}{ Gender } & Male & $1,704(46.1)$ & $194.2(34.7)$ & $1,352(46.7)$ & $195.7(34.2)$ & $1,703(49.6)$ & $197.0(35.0)$ \\
\hline & Female & $1,839(49.8)$ & $197.9(31.3)$ & $1,481(51.2)$ & $198.8(31.8)$ & $1,681(49.0)$ & $200.9(32.8)$ \\
\hline \multirow[t]{2}{*}{ Level } & Senior high & $969(26.2)$ & $194.1(34.1)$ & $505(17.5)$ & $203.1(30.3)$ & $445(13.0)$ & $194.9(27.8)$ \\
\hline & Junior high & $2,725(3.8)$ & $200.9(29.7)$ & $2,387(82.5)$ & $196.0(33.3)$ & $2,989(87.0)$ & $199.6(34.9)$ \\
\hline \multirow[t]{7}{*}{ School } & A & $478(12.9)$ & $186.3(30.7)$ & $433(15.0)$ & $190.5(32.6)$ & $689(19.4)$ & $192.9(33.6)$ \\
\hline & B & $454(12.3)$ & $194.9(27.2)$ & $164(5.7)$ & $193.8(28.8)$ & $408(11.5)$ & $193.4(26.6)$ \\
\hline & $\mathrm{C}$ & $822(22.3)$ & $193.4(34.4)$ & $819(28.3)$ & $192.0(33.7)$ & $856(24.1)$ & $203.8(34.8)$ \\
\hline & $\mathrm{D}$ & $77(2.1)$ & $186.0(33.9)$ & 73.(2.5) & $195.5(30.4)$ & $133(3.8)$ & $197.4(34.2)$ \\
\hline & $\mathrm{E}$ & $95(2.6)$ & $190.1(30.5)$ & $39(1.3)$ & $214.1(24.8)$ & $87(2.5)$ & 196.5(32.6) \\
\hline & $\mathrm{F}$ & $1114(30.2)$ & $203.0(33.2)$ & $713(24.7)$ & $206.1(32.0)$ & $625(17.6)$ & 205.4 (35.7) \\
\hline & G & $654(17.7)$ & $196.4(34.6)$ & $651(22.5)$ & $193.9(32.8)$ & $636(17.9)$ & 196.9 (34.9) \\
\hline Total & & 3,694 (100) & $195.9(33.0)$ & $2,892(100)$ & $197.3(32.9)$ & $3,434(100)$ & $198.9(34.0)$ \\
\hline
\end{tabular}

Junior high schools A, C, D, E, G, F; Senior high schools B and F

Fig. 2 The error sum of squares that decides the optimal $\mathrm{k}$

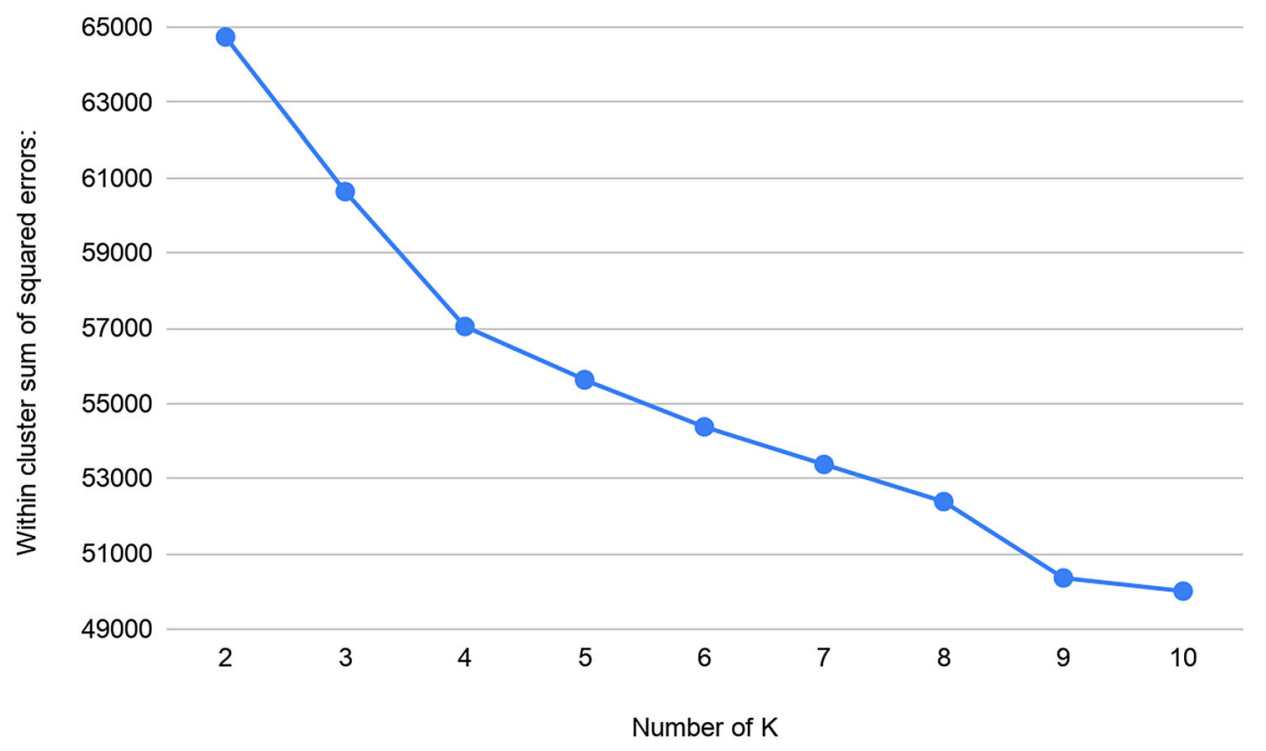

We visualized clusters by background variables (Fig. 3) and the eight SDLR latent variables (Fig. 4). The following are shared characteristics of each cluster.

- Cluster 1 (1,924 students, slightly below average SDLR, mostly junior high girls): Cluster 1 consisted of girls who were in piloting classes and were located mostly in rural schools in eastern Taiwan.

- Cluster 2 (3,041 students, slightly below average SDLR, mostly junior high girls): Cluster 2 included the below average SDLR girls located at northern metropolitan Taiwan. Moreover, they were control group students.
- Cluster 3 (2,351 students, low SDLR, mostly junior high boys): Cluster 3 had the lowest scoring boys from metro areas in northern Taiwan. They were also students from piloting classes.

- Cluster 4 (2,444 students, above average SDLR, mostly junior high boys): Cluster 4 represented the highestperforming SDLR students among all participants. They were most likely to have studied at either metropolitan junior high schools in northern Taiwan or rural senior high schools at eastern Taiwan. Mostly, they were students who enjoyed their learning experience in piloting classes or the $\mathrm{nCG}$. 


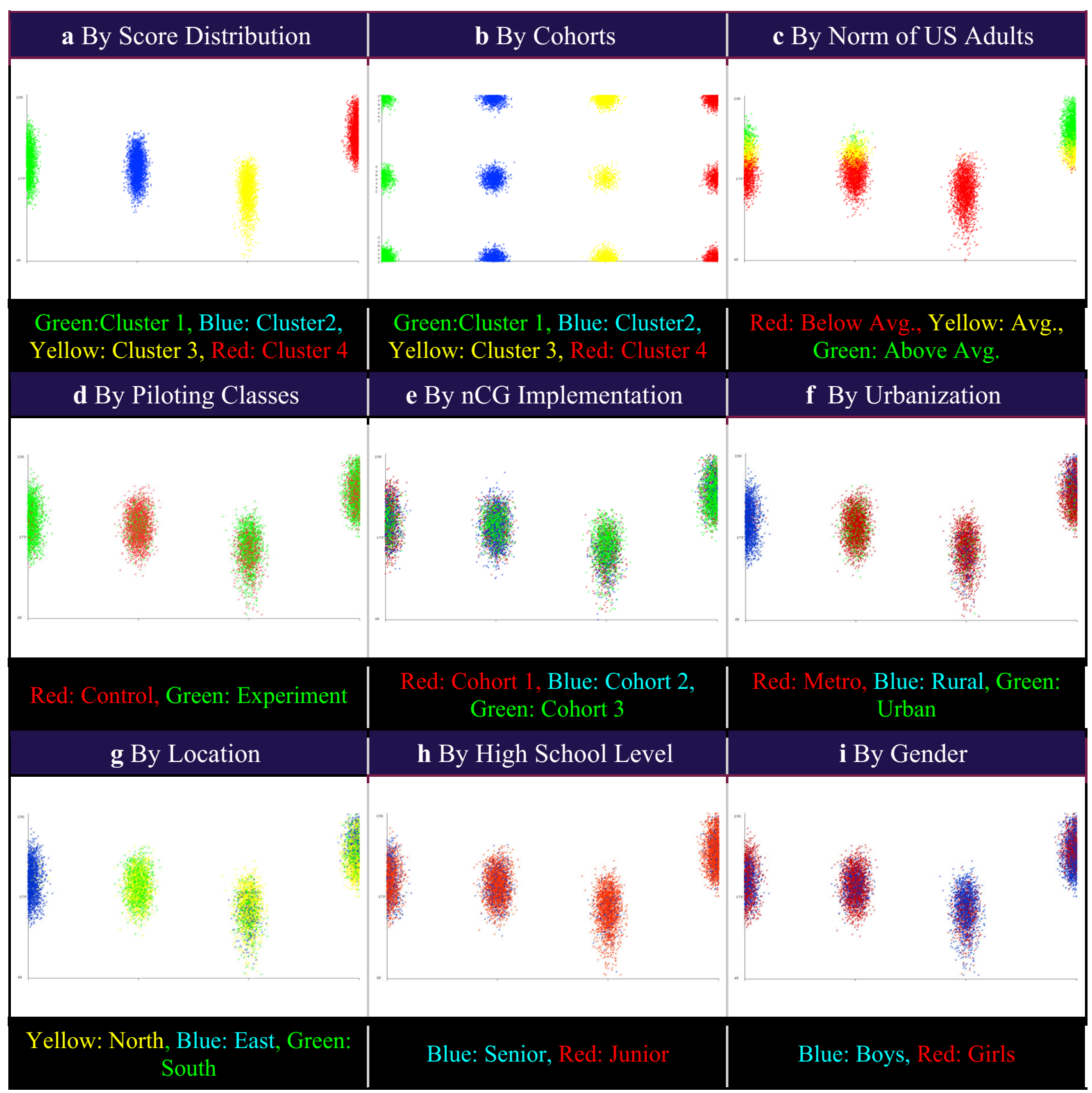

Fig. 3 Visualizing student characteristic of the four clusters

There are some notable differences across SDLR clusters. For example, students who studied in rural schools in eastern Taiwan (generally considered a less developed area) could have high SDLR. Interestingly, students from metropolitan northern Taiwan have both the highest (Cluster $4=237.24$ ) and lowest (Cluster $3=160.66$ ) scores. Moreover, boys had a wider variety in SDLR, but girls deviated less from the mean. Cohort 3 students appeared to be polarized. Some of them performed well under nCG (Cluster 4) while others performed poorly (Cluster 3) in SDLR after nCG was implemented.

We then investigated cluster differences with regard to the eight latent variables in SDLR. Figure 4 displays performance matrices of the eight SDLR latent variables among the four clusters by the shape of the polygons. Cluster 4 was the nCG students and did the best overall in SDLR, doing especially well on the AR, SU LL, IL, and CT. Cluster 3 had the lowest ratings; five of eight latent variables were lower than 3 (the middle value), and its SC 


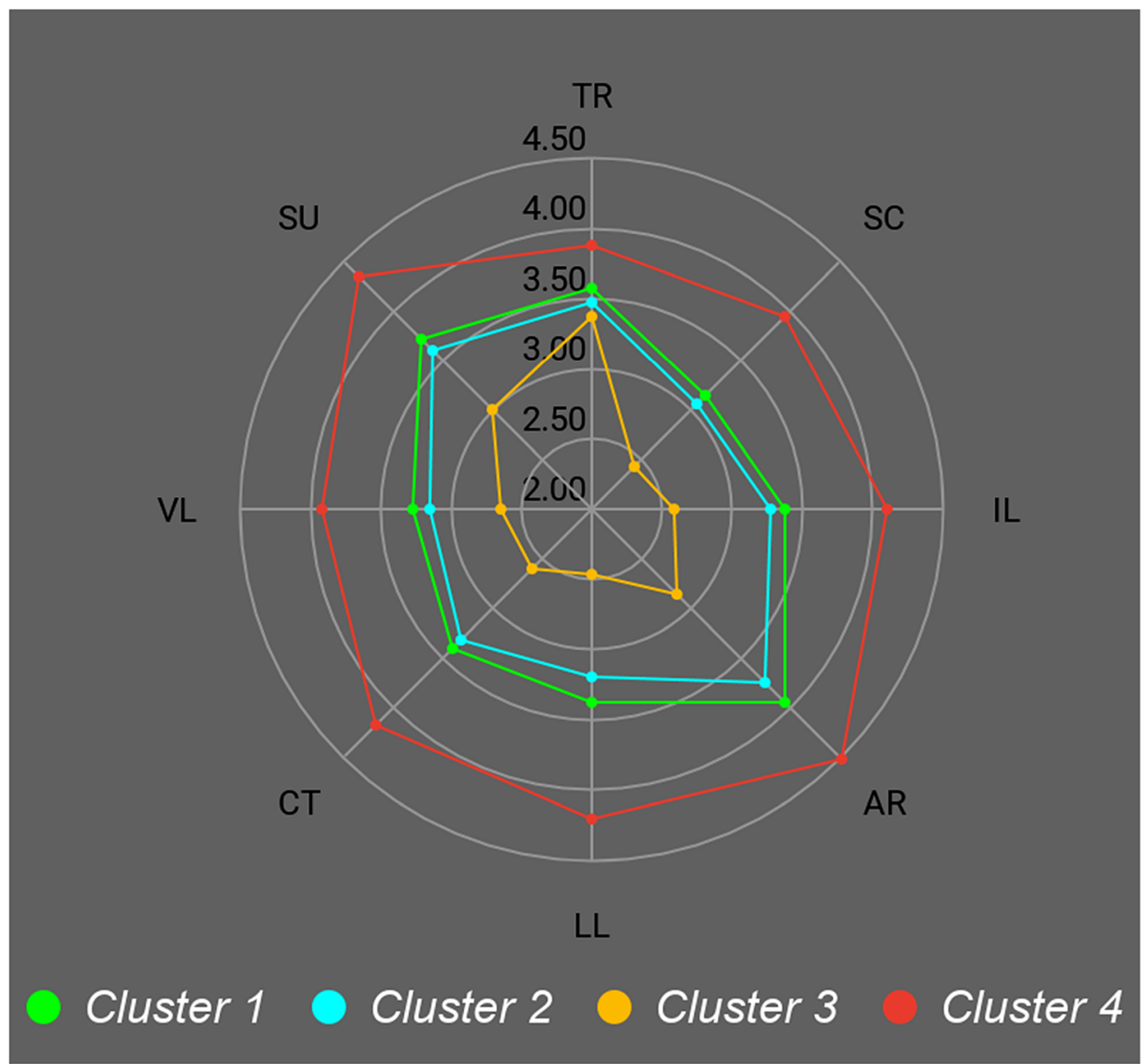

Fig. 4 A Radar chart displaying performance of eight SDLR latents among four clusters

and LL were especially low. Clusters 1 and 2 were similar in shape, but 1 was slightly better than 2 in all aspects.

\section{RQ1-2: Can SDLR differences be found among demographic variables?}

Comparison of means among cohorts by gender, school level, each specific school, and the total were conducted. Table 3 shows the effects of nCG over three different time periods. There exists statistical significance of better SDLR score comparing Cohorts 3 to 1 in total, female students, junior high-school students, as well as students in school A and $\mathrm{C}$ at a significant level of 0.01 . Interestingly, senior high-school students and students in School E had Cohort 2 outperformed over Cohorts 1 and 3 .

To further examine the effects of demographic variables on SDLR, a stepwise multiple regression was conducted on the automatic linear modeling procedure in SPSS 21.0. The SDLR score was used as the dependent variable and demographics (i.e., gender, pilot group, cohort, school level, geographical location, and urbanization; see Fig. 5) were entered as predictors. Being the main intervention variable of the study, $\mathrm{nCG}$ also was entered as one of the predictors. The procedure removed observations with missing values and created a single, standard model with smallest AIC value to explain relationships among fields. Five of the predictors were tested with significant effects with importance indices Geo (importance $=0.44$, $p=0.000$ ), pilot groups (importance $=0.15, p=0.000$ ), gender (importance $=0.17, p=0.000$ ), $\mathrm{nCG}$ (importance $=0.19, \quad p=0.000$ ), and school level (importance $=0.05, p=0.009)$. A significant regression equation was found $(F[5,9,754]=50.05, p=0.005$; see Fig. 6$)$. Taking a Cohort 3 senior high-school girl who was in the pilot group and lived in eastern Taiwan as reference, the participant's predicted SDLR score equals to 187.88 (intercept $)+7.21$ (east) +3.75 (pilot) $+3.47 \quad$ (girl) +0 $($ Cohort 3 as baseline $)+2.50$ (senior $)=204.81$, where the $p$ values for all coefficients $<0.005$. However, the adjusted $R^{2}$ was only $2.5 \%$. We concluded that there existed significant, but limited, effects to SDLR among the five 
Table 3 Mean value and one-way Anova result for gender, level, and schools in SDLR at different times

\begin{tabular}{|c|c|c|c|c|c|c|c|c|c|c|c|c|}
\hline \multirow[t]{2}{*}{ Cohort } & \multirow[t]{2}{*}{ Total } & \multicolumn{2}{|l|}{ Gender } & \multicolumn{2}{|l|}{ Level } & \multicolumn{7}{|c|}{ School } \\
\hline & & M & $\mathrm{F}$ & $\mathrm{J}$ & S & A & B & $\mathrm{C}$ & D & E & $\mathrm{F}$ & G \\
\hline 1 & 195.9 & 194.1 & 198.0 & 194.1 & 200.9 & 186.3 & 194.9 & 193.4 & 186.0 & 190.1 & 203.0 & 196.4 \\
\hline 2 & 197.3 & 195.7 & 198.8 & 196.0 & 203.1 & 190.5 & 193.8 & 196.0 & 195.5 & 214.1 & 206.0 & 193.9 \\
\hline 3 & 198.9 & 197.2 & 201.1 & 199.8 & 194.8 & 192.9 & 193.4 & 203.8 & 197.4 & 196.5 & 205.4 & 196.9 \\
\hline$F$ & 7.56 & 3.35 & 4.68 & 21.04 & 10.10 & 5.73 & 0.37 & 21.08 & 3.05 & 8.55 & 2.05 & 1.44 \\
\hline$p$ value & 0.0001 & 0.035 & 0.009 & 0.000 & 0.000 & 0.003 & 0.690 & 0.000 & 0.049 & 0.000 & 0.130 & 0.238 \\
\hline Post hoc & $3>1$ & - & $3>1$ & $3>1=2$ & $2=1>3$ & $3>1$ & - & $3>1=2$ & - & $2>1=3$ & - & - \\
\hline
\end{tabular}

$M$ Male, $F$ Female; $J$ Junior high, $S$ Senior high

Significant level $=0.01$ The Levene test of variance among cohorts is $(F=3.105, p=0.05)$

\section{Model Building Summary \\ Target: SDLRS score}

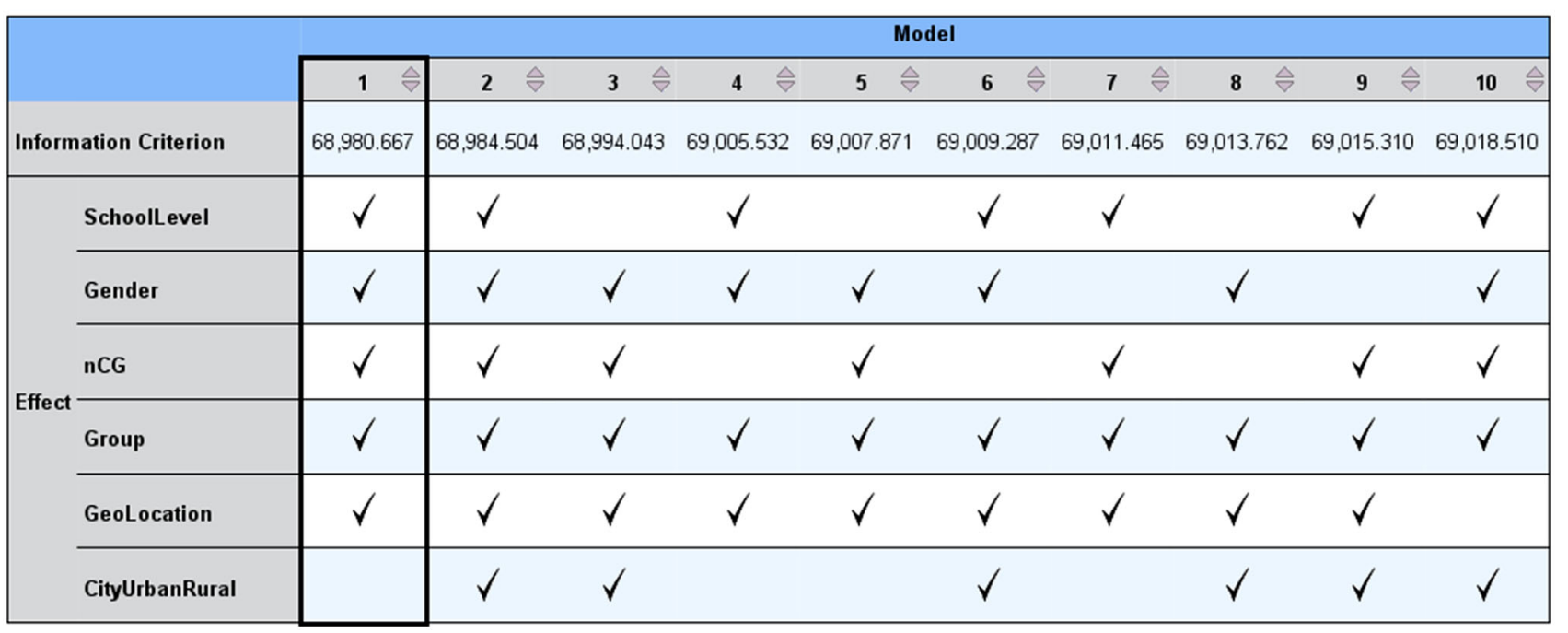

Fig. 5 Best subsets model-building summary using AIC

demographic variables: nCG, gender, pilot programs, school level, and geographical locations.

\section{RQ1-3: Can implementation of nCG improve SDLR?}

Before the implementation, the average score was $195.9 \pm 33.0$ (mean and standard deviation) in Cohort 1. Part of the Cohort 2 piloted nCG-oriented SDL programs before the nCG implementation; the average score of the cohort was $197.3 \pm 32.9$. After a semester of nCG implementation, Cohort 3 had an average score of $198.9 \pm 34.1$. The trend showed a minor but statistically significant improvement of SDLR between nCG implementation $(F=7.56, p=0.001)$. To understand the effects of nCG implementation, we separated SDLR scores of three business-as-usual groups and assumed score improvements in Cohort 3 controls (i.e., $3 \mathrm{C}>2 \mathrm{C}=1 \mathrm{C}$ ). Table 3 reveals that SDLR among controls received minor, insignificant improvement in ANOVA. We further evaluated differences among eight SDLR latent variables and three cohorts. Results showed that $3 \mathrm{C}$ had higher scores of $\mathrm{AR}$ and VL. The two inconsistent results indicated that developing SDL takes more time (see also Table 6). Interestingly, 2C and 3C had lower scores in TR. We 

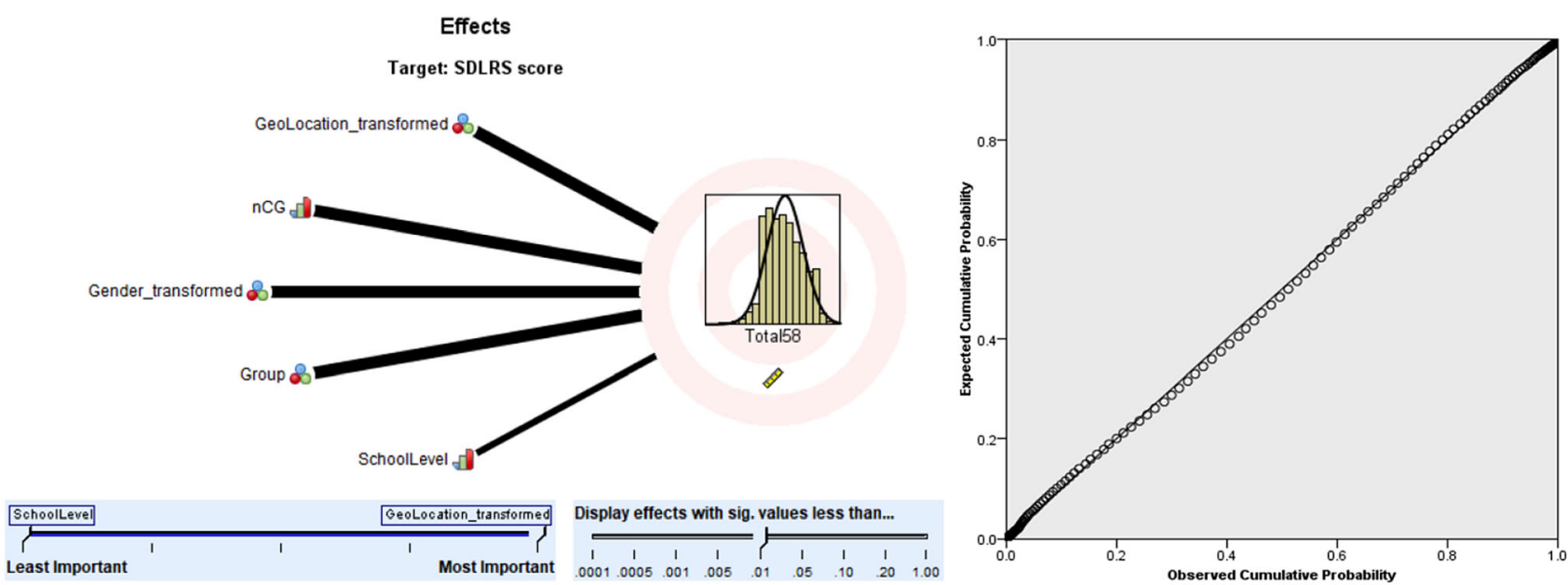

Fig. 6 Predictor importance of the demographic predictors and normal P-P plot of standardized residual of the model

Table 4 Mean comparisons of SDLR scores among three business-as-usual groups

\begin{tabular}{|c|c|c|c|c|c|c|}
\hline SDLR Latents & Level & M & SD & $F$ & $p$ & Post hoc \\
\hline \multirow[t]{3}{*}{ Total } & Cohort 1C & 193.26 & 31.48 & 1.13 & 0.322 & \\
\hline & Cohort $2 \mathrm{C}$ & 193.34 & 32.10 & & & \\
\hline & Cohort 3C & 194.84 & 31.82 & & & \\
\hline \multirow[t]{3}{*}{ TR } & Cohort 1C & 3.58 & 0.63 & 11.82 & 0.000 & $1>2=3$ \\
\hline & Cohort $2 \mathrm{C}$ & 3.48 & 0.63 & & & \\
\hline & Cohort 3C & 3.49 & 0.62 & & & \\
\hline \multirow[t]{3}{*}{$\mathrm{SC}$} & Cohort 1C & 3.03 & 0.72 & 6.21 & 0.001 & $2>1$ \\
\hline & Cohort 2C & 3.13 & 0.74 & & & \\
\hline & Cohort 3C & 3.09 & 0.75 & & & \\
\hline \multirow[t]{3}{*}{ IL } & Cohort 1C & 3.26 & 0.85 & 0.81 & 0.445 & \\
\hline & Cohort 2C & 3.26 & 0.82 & & & \\
\hline & Cohort 3C & 3.29 & 0.82 & & & \\
\hline \multirow[t]{3}{*}{$\mathrm{AR}$} & Cohort $1 \mathrm{C}$ & 3.61 & 1.02 & 5.83 & 0.003 & $3>1$ \\
\hline & Cohort $2 \mathrm{C}$ & 3.68 & 1.03 & & & \\
\hline & Cohort 3C & 3.73 & 0.99 & & & \\
\hline \multirow[t]{3}{*}{ LL } & Cohort 1C & 3.23 & 0.77 & 0.24 & 0.791 & \\
\hline & Cohort $2 \mathrm{C}$ & 3.23 & 0.77 & & & \\
\hline & Cohort 3C & 3.25 & 0.77 & & & \\
\hline \multirow[t]{3}{*}{$\mathrm{CT}$} & Cohort 1C & 3.30 & 0.80 & 1.74 & 0.175 & \\
\hline & Cohort $2 \mathrm{C}$ & 3.34 & 0.79 & & & \\
\hline & Cohort 3C & 3.36 & 0.79 & & & \\
\hline \multirow[t]{3}{*}{ VL } & Cohort $1 \mathrm{C}$ & 3.10 & 0.72 & 53.17 & 0.000 & $3>2=1$ \\
\hline & Cohort 2C & 3.14 & 0.71 & & & \\
\hline & Cohort 3C & 3.36 & 0.75 & & & \\
\hline \multirow[t]{3}{*}{ SU } & Cohort $1 \mathrm{C}$ & 3.59 & 0.69 & 1.32 & 0.267 & \\
\hline & Cohort $2 \mathrm{C}$ & 3.58 & 0.70 & & & \\
\hline & Cohort 3C & 3.62 & 0.68 & & & \\
\hline
\end{tabular}

Cohort 1C $(n=1,565)$, Cohort $2 \mathrm{C}(n=1,227)$, Cohort $3(n=1,460)$

Levene test of homogeneity of variances ranged from 0.118 to 0.980 among the paired comparison 
Table 5 Mean Comparisons of SDLR scores among three piloting groups

\begin{tabular}{|c|c|c|c|c|c|c|}
\hline SDLR Latents & Level & M & SD & $F$ & $p$ & Post hoc \\
\hline \multirow[t]{3}{*}{ Total $^{\mathrm{a}}$} & Cohort 1E & 197.78 & 34.01 & 8.73 & 0.001 & $3>1$ \\
\hline & Cohort 2E & 200.17 & 33.26 & & & \\
\hline & Cohort 3E & 201.97 & 34.34 & & & \\
\hline \multirow[t]{3}{*}{ TR } & Cohort 1E & 3.65 & 0.61 & 10.08 & 0.000 & $3=1>2$ \\
\hline & Cohort 2E & 3.54 & 0.64 & & & \\
\hline & Cohort 3E & 3.64 & 0.66 & & & \\
\hline \multirow[t]{3}{*}{$\mathrm{SC}^{\mathrm{a}}$} & Cohort 1E & 3.12 & 0.77 & 13.59 & 0.000 & $3=2>1$ \\
\hline & Cohort 2E & 3.25 & 0.75 & & & \\
\hline & Cohort 3E & 3.20 & 0.79 & & & \\
\hline \multirow[t]{3}{*}{ IL } & Cohort 1E & 3.33 & 0.86 & 7.22 & 0.001 & $2>1$ \\
\hline & Cohort 2E & 3.42 & 0.83 & & & \\
\hline & Cohort 3E & 3.38 & 0.86 & & & \\
\hline \multirow[t]{3}{*}{ AR } & Cohort 1E & 3.78 & 1.00 & 3.53 & 0.030 & \\
\hline & Cohort 2E & 3.87 & 1.00 & & & \\
\hline & Cohort 3E & 3.82 & 1.03 & & & \\
\hline \multirow[t]{3}{*}{ LL } & Cohort 1E & 3.30 & 0.81 & 11.34 & 0.000 & $3>1$ \\
\hline & Cohort 2E & 3.37 & 0.80 & & & \\
\hline & Cohort 3E & 3.41 & 0.82 & & & \\
\hline \multirow[t]{3}{*}{$\mathrm{CT}^{\mathrm{a}}$} & Cohort 1E & 3.34 & 0.83 & 13.45 & 0.000 & $3=2>1$ \\
\hline & Cohort 2E & 3.47 & 0.79 & & & \\
\hline & Cohort 3E & 3.45 & 0.86 & & & \\
\hline \multirow[t]{3}{*}{$\mathrm{VL}^{\mathrm{a}}$} & Cohort 1E & 3.18 & 0.75 & 74.18 & 0.000 & $3>2=1$ \\
\hline & Cohort 2E & 3.21 & 0.76 & & & \\
\hline & Cohort 3E & 3.44 & 0.80 & & & \\
\hline \multirow[t]{3}{*}{$\mathrm{SU}^{\mathrm{a}}$} & Cohort $1 \mathrm{E}$ & 3.70 & 0.68 & 1.56 & 0.190 & \\
\hline & Cohort 2E & 3.74 & 0.68 & & & \\
\hline & Cohort 3E & 3.72 & 0.75 & & & \\
\hline
\end{tabular}

Cohort $1 \mathrm{E}(n=2,129)$, Cohort $2 \mathrm{E}(n=1,665)$, Cohort $3 \mathrm{E}(n=1,974)$

${ }^{\mathrm{a}}$ Levene test of homogeneity $<0.01$, additional Welch test was re-conducted

speculated that Cohorts $2 \mathrm{C}$ and $3 \mathrm{C}$ students experienced uncertainty when nCG was introduced (Table 4).

\section{RQ2-1: Can SDL piloting programs in high schools improve SDLR? In what sub-domains were they improved?}

For RQ2-1, we assumed that the SDL piloting programs would have performed differently after the implementation of piloting courses and after the onboarding of nCG (i.e., $3 \mathrm{E}>2 \mathrm{E}>1 \mathrm{E}$ ). Also, we noticed that a few studies showed SDLR increases with program progression (e.g., Kocaman et al., 2009). Therefore, comparison among the three pilot groups was conducted. Table 5 shows that SC, IL, LL, CT, VL, and the total all increased with program progression. Again, a further analysis separating junior and senior high-school students was conducted; VL progression was seen only in senior high-school students (see Table 6).
Furthermore, we expected that no differences existed at the very beginning of our study $(1 \mathrm{C}=1 \mathrm{E})$, followed by better SDLR performances in Cohorts 2 and 3 (2E $>2 \mathrm{C}$ and $3 \mathrm{E}>3 \mathrm{C}$ ). Table 7 reveals that $1 \mathrm{E}$ performed 5 of 8 latent variables better than $1 \mathrm{C}$, and that Cohort 2 and 3 pilots outperformed than their business-as-usual counterparts in 7 and all 8 latent variables. We concluded that the pilot classes not only performed better over time, but also performed better than controls in all three cohorts. However, given that participants were fully aware of their experimental assignments (i.e., 1E) in schools, the Hawthorne effect may have existed in these experimental groups from the very beginning. Moreover, the literature indicated that SDLR is positively correlated to the age or education level of learners (e.g., Slater et al., 2017). Therefore, we further separated junior and senior highschool students as separate groups for the same analysis. 
Table 6 Mean comparisons of SDLR scores among three piloting groups by separating junior and senior high school students

\begin{tabular}{|c|c|c|c|c|c|c|c|c|c|c|c|}
\hline \multirow[t]{2}{*}{ SDLR Latent } & \multirow[t]{2}{*}{ Level } & \multicolumn{5}{|c|}{ Junior high } & \multicolumn{5}{|c|}{ Senior high } \\
\hline & & M & SD & $F$ & $p$ & Post hoc & M & SD & $F$ & $p$ & Post hoc \\
\hline \multirow[t]{3}{*}{ Total } & Cohort 1E & 195.12 & 34.56 & 18.15 & 0.000 & $3>1=2$ & 206.11 & 30.80 & 0.57 & 0.568 & \\
\hline & Cohort 2E & 198.26 & 33.78 & & & & 207.60 & 30.04 & & & \\
\hline & Cohort 3E & 201.80 & 35.45 & & & & 210.86 & 35.31 & & & \\
\hline \multirow[t]{3}{*}{ TR } & Cohort 1E & 3.66 & 0.62 & 11.11 & 0.000 & $3=1>2$ & 3.64 & 0.58 & 9.09 & 0.000 & $2>1$ \\
\hline & Cohort 2E & 3.55 & 0.64 & & & & 3.47 & 0.62 & & & \\
\hline & Cohort 3E & 3.64 & 0.66 & & & & 3.63 & 0.71 & & & \\
\hline \multirow[t]{3}{*}{$\mathrm{SC}$} & Cohort 1E & 3.08 & 0.78 & 13.32 & 0.000 & $3=2>1$ & 3.24 & 0.71 & 5.16 & 0.006 & $2>1$ \\
\hline & Cohort $2 \mathrm{E}$ & 3.21 & 0.76 & & & & 3.40 & 0.69 & & & \\
\hline & Cohort 3E & 3.20 & 0.80 & & & & 3.40 & 0.86 & & & \\
\hline \multirow[t]{3}{*}{ IL } & Cohort 1E & 3.28 & 0.88 & 10.23 & 0.000 & $3=2>1$ & 3.46 & 0.79 & 0.88 & 0.417 & \\
\hline & Cohort 2E & 3.39 & 0.85 & & & & 3.53 & 0.77 & & & \\
\hline & Cohort 3E & 3.40 & 0.89 & & & & 3.43 & 0.92 & & & \\
\hline \multirow[t]{3}{*}{ AR } & Cohort 1E & 3.69 & 1.03 & 8.18 & 0.000 & $3>1$ & 4.09 & 0.82 & 1.39 & 0.251 & \\
\hline & Cohort 2E & 3.79 & 1.03 & & & & 4.18 & 0.79 & & & \\
\hline & Cohort 3E & 3.81 & 1.03 & & & & 4.12 & 0.98 & & & \\
\hline \multirow[t]{3}{*}{ LL } & Cohort 1E & 3.21 & 0.82 & 26.30 & 0.000 & $3>2>1$ & 3.56 & 0.72 & 1.20 & 0.301 & \\
\hline & Cohort $2 \mathrm{E}$ & 3.31 & 0.81 & & & & 3.60 & 0.68 & & & \\
\hline & Cohort 3E & 3.40 & 0.82 & & & & 3.74 & 0.70 & & & \\
\hline \multirow[t]{3}{*}{ CT } & Cohort 1E & 3.29 & 0.84 & 18.23 & 0.000 & $3=2>1$ & 3.52 & 0.75 & 2.14 & 0.118 & \\
\hline & Cohort 2E & 3.43 & 0.81 & & & & 3.63 & 0.71 & & & \\
\hline & Cohort 3E & 3.45 & 0.86 & & & & 3.57 & 0.79 & & & \\
\hline \multirow[t]{3}{*}{ VL } & Cohort $1 \mathrm{E}$ & 3.12 & 0.77 & 93.18 & $0.000^{\mathrm{a}}$ & $3>2=1$ & 3.35 & 0.69 & 5.69 & 0.004 & $3>1$ \\
\hline & Cohort 2E & 3.16 & 0.76 & & & & 3.43 & 0.71 & & & \\
\hline & Cohort $3 \mathrm{E}$ & 3.44 & 0.80 & & & & 3.74 & 0.69 & & & \\
\hline \multirow[t]{3}{*}{ SU } & Cohort $1 \mathrm{E}$ & 3.66 & 0.69 & 3.68 & $0.039^{\mathrm{a}}$ & & 3.84 & 0.62 & 1.64 & 0.194 & \\
\hline & Cohort $2 \mathrm{E}$ & 3.70 & 0.69 & & & & 3.90 & 0.61 & & & \\
\hline & Cohort 3E & 3.72 & 0.75 & & & & 3.74 & 0.82 & & & \\
\hline
\end{tabular}

Cohort 1E (Sr. $n=515$; Jr. $n=1,614)$, Cohort 2E (Sr. $n=341$; jr. $n=1,324)$, Cohort 3E (Sr. $n=37$; Jr. $n=1,937)$

${ }^{\mathrm{a}}$ Levene test of homogeneity $<0.01$, additional Welch test was re-conducted

Table 8 reveals different trends in senior and junior high-school piloting students. Junior high-school students had only three significant latents (SC, AR, and SU) before nCG (Cohort 1), but increased to 7 latent variables in pilots (Cohort 2) and after nCG (Cohort 3). On the contrary, senior high students had 9 significant latent variables in Cohort 1 but decreased to 4 in Cohort 3 .

\section{RQ2-2: Do those SDL piloting programs reveal particular advantages with regard to these SDLR latent variables?}

Four schools in the study implemented SDL pilot programs one year before nCG started. We compared SDLR scores within the four pilots (i.e., $A_{E}, C_{E}, D_{E}$, and $F_{E}$ ). Students in School $\mathrm{F}$ had the highest SDLR scores among all piloting peers as well as in the grand total (see Table 9). School F also had outstanding performances in TR, AR, LL, SU, and VL. Among the other three schools, School A performed well in TR, School C in SC and SU, and School D in CT.

\section{Discussion}

\section{Identification of possible SDL typology in Taiwan high-school students}

As evident from this study, the average score of Taiwan high-school students' SDLR fell under the average score as defined in Guglielmino's scale, and expressed wider variations. Our results correspond with those of other studies regarding positive correlations between SDLR and age/ 
Table 7 Comparing pilots and business-as-usual participants in three cohorts

\begin{tabular}{|c|c|c|c|c|c|c|c|c|c|c|c|}
\hline Cohort & Group & & SDLRS & TR & $\mathrm{SC}$ & IL & $\mathrm{AR}$ & LL & CT & VL & SU \\
\hline \multirow[t]{4}{*}{1} & \multirow[t]{2}{*}{ Ctrl } & Mean & 193.26 & 3.58 & 3.03 & 3.26 & 3.61 & 3.23 & 3.30 & 3.10 & 3.59 \\
\hline & & SD & 31.48 & 0.63 & 0.72 & 0.85 & 1.02 & 0.77 & 0.80 & 0.72 & 0.69 \\
\hline & \multirow[t]{2}{*}{ Exp } & Mean & $197.78 * *$ & $3.65 * *$ & $3.12 * *$ & 3.33 & $3.78 * *$ & 3.30 & 3.34 & $3.18 * *$ & $3.70 * *$ \\
\hline & & SD & 34.01 & 0.61 & 0.77 & 0.86 & 1.00 & 0.81 & 0.83 & 0.75 & 0.68 \\
\hline \multirow[t]{4}{*}{2} & \multirow[t]{2}{*}{ Ctrl } & Mean & 193.34 & 3.48 & 3.13 & 3.26 & 3.68 & 3.23 & 3.34 & 3.14 & 3.58 \\
\hline & & SD & 32.10 & 0.63 & 0.74 & 0.82 & 1.03 & 0.77 & 0.79 & 0.71 & 0.70 \\
\hline & \multirow[t]{2}{*}{ Exp } & Mean & $200.17 * *$ & 3.54 & $3.25 * *$ & $3.42 * *$ & $3.87 * *$ & $3.37 * *$ & $3.47 * *$ & $3.21 * *$ & $3.74 * *$ \\
\hline & & SD & 33.26 & 0.64 & 0.75 & 0.83 & 1.00 & 0.80 & 0.79 & 0.76 & 0.68 \\
\hline \multirow[t]{4}{*}{3} & \multirow[t]{2}{*}{ Ctrl } & Mean & 194.84 & 3.49 & 3.09 & 3.29 & 3.73 & 3.25 & 3.36 & 3.36 & 3.62 \\
\hline & & SD & 31.82 & 0.62 & 0.75 & 0.82 & 0.99 & 0.77 & 0.79 & 0.75 & 0.68 \\
\hline & \multirow[t]{2}{*}{ Exp } & Mean & $201.97 * *$ & $3.64 * *$ & $3.21 * *$ & $3.40 * *$ & $3.82 * *$ & $3.41 * *$ & $3.45 * *$ & $3.44 * *$ & $3.72 * *$ \\
\hline & & SD & 35.45 & 0.66 & 0.80 & 0.89 & 1.03 & 0.82 & 0.86 & 0.80 & 0.75 \\
\hline
\end{tabular}

Cohort $1(n=3,694)$, Cohort $2(n=2,892)$, Cohort $3(n=3,434)$

**significant level at 0.01

Table 8 Comparing pilots and business-as-usual participants in three cohorts by separating junior and senior high school students

\begin{tabular}{|c|c|c|c|c|c|c|c|c|c|c|c|c|}
\hline Cohort & & Group & & SDLRS & TR & $\mathrm{SC}$ & IL & $\mathrm{AR}$ & LL & CT & VL & SU \\
\hline \multirow[t]{8}{*}{1} & \multirow[t]{4}{*}{$\mathrm{Sr}$} & \multirow[t]{2}{*}{ Ctrl } & Mean & 194.94 & 3.37 & 3.16 & 3.33 & 3.76 & 3.34 & 3.38 & 3.19 & 3.65 \\
\hline & & & $S D$ & 27.17 & 0.60 & 0.66 & 0.74 & 0.89 & 0.65 & 0.73 & 0.62 & 0.63 \\
\hline & & \multirow[t]{2}{*}{ Exp } & Mean & $206.11 * *$ & $3.64 * *$ & 3.24 & 3.46 & $4.09 * *$ & $3.56^{* *}$ & $3.52 * *$ & $3.35 * *$ & $3.84 * *$ \\
\hline & & & $S D$ & 30.80 & 0.58 & 0.71 & 0.79 & 0.82 & 0.72 & 0.75 & 0.69 & 0.62 \\
\hline & \multirow[t]{4}{*}{$\mathrm{Jr}$} & \multirow[t]{2}{*}{ Ctrl } & Mean & 192.58 & 3.67 & 2.98 & 3.23 & 3.55 & 3.19 & 3.27 & 3.07 & 3.57 \\
\hline & & & $S D$ & 33.06 & 0.62 & 0.74 & 0.89 & 1.07 & 0.81 & 0.83 & 0.76 & 0.71 \\
\hline & & \multirow[t]{2}{*}{ Exp } & Mean & 195.12 & 3.66 & $3.08 * *$ & 3.28 & $3.69 * *$ & 3.21 & 3.29 & 3.12 & $3.66^{* *}$ \\
\hline & & & $S D$ & 34.56 & 0.62 & 0.78 & 0.88 & 1.03 & 0.82 & 0.84 & 0.77 & 0.69 \\
\hline \multirow[t]{8}{*}{2} & \multirow[t]{4}{*}{$\mathrm{Sr}$} & \multirow[t]{2}{*}{ Ctrl } & Mean & 193.77 & 3.34 & 3.20 & 3.22 & 3.83 & 3.32 & 3.36 & 3.22 & 3.55 \\
\hline & & & $S D$ & 28.78 & 0.55 & 0.65 & 0.79 & 0.91 & 0.66 & 0.61 & 0.63 & 0.65 \\
\hline & & \multirow[t]{2}{*}{ Exp } & Mean & $207.60 * *$ & 3.47 & $3.40 * *$ & $3.53 * *$ & $4.18 * *$ & $3.60 * *$ & $3.63 * *$ & $3.43 * *$ & $3.90 * *$ \\
\hline & & & $S D$ & 30.04 & 0.62 & 0.69 & 0.77 & 0.79 & 0.68 & 0.71 & 0.71 & 0.61 \\
\hline & \multirow[t]{4}{*}{$\mathrm{Jr}$} & \multirow[t]{2}{*}{ Ctrl } & Mean & 193.27 & 3.50 & 3.12 & 3.27 & 3.65 & 3.22 & 3.33 & 3.12 & 3.59 \\
\hline & & & $S D$ & 32.59 & 0.64 & 0.76 & 0.83 & 1.04 & 0.78 & 0.81 & 0.72 & 0.71 \\
\hline & & \multirow[t]{2}{*}{ Exp } & Mean & $198.26 * *$ & 3.55 & $3.21 * *$ & $3.39 * *$ & $3.79 * *$ & $3.31 * *$ & $3.43 * *$ & 3.16 & $3.70 * *$ \\
\hline & & & $S D$ & 33.78 & 0.64 & 0.76 & 0.85 & 1.03 & 0.81 & 0.81 & 0.76 & 0.69 \\
\hline \multirow[t]{8}{*}{3} & \multirow[t]{4}{*}{$\mathrm{Sr}$} & \multirow[t]{2}{*}{ Ctrl } & Mean & 193.38 & 3.44 & 3.01 & 3.20 & 3.80 & 3.27 & 3.32 & 3.41 & 3.62 \\
\hline & & & $S D$ & 26.59 & 0.51 & 0.65 & 0.73 & 0.87 & 0.67 & 0.72 & 0.70 & 0.59 \\
\hline & & \multirow[t]{2}{*}{ Exp } & Mean & $210.86^{* *}$ & 3.63 & $3.40 * *$ & 3.43 & 4.12 & $3.74 * *$ & 3.57 & $3.74 * *$ & 3.74 \\
\hline & & & $S D$ & 35.31 & 0.71 & 0.86 & 0.92 & 0.98 & 0.70 & 0.79 & 0.69 & 0.82 \\
\hline & \multirow[t]{4}{*}{$\mathrm{Jr}$} & \multirow[t]{2}{*}{ Ctrl } & Mean & 195.41 & 3.51 & 3.12 & 3.33 & 3.70 & 3.24 & 3.37 & 3.34 & 3.63 \\
\hline & & & $S D$ & 33.63 & 0.65 & 0.79 & 0.84 & 1.03 & 0.81 & 0.82 & 0.76 & 0.71 \\
\hline & & \multirow[t]{2}{*}{ Exp } & Mean & $201.80 * *$ & $3.64 * *$ & $3.20 * *$ & 3.40 & $3.81 * *$ & $3.41 * *$ & 3.45 & $3.44 * *$ & $3.72 * *$ \\
\hline & & & $S D$ & 35.44 & 0.66 & 0.80 & 0.89 & 1.03 & 0.82 & 0.86 & 0.80 & 0.75 \\
\hline
\end{tabular}

Sr. senior high, Jr. junior high, Cohort 1 (Sr. $n=969 ;$ Jr. $n=2,725)$, Cohort 2 (Sr. $n=505$; Jr. $n=2,387)$, Cohort 3 (Sr. $n=445$ Jr. $n=2,989$ ) **significant level at 0.01

educational levels (Kocaman et al., 2009), where people who completed more years in schools tended to have higher SDLR (Brockett, 1985). Additionally, the results of the present study suggested four homogeneous subgroups among students in SDLR (Cluster 1: low SDLR rural girls who were not used to piloting classes; Cluster 2: low SDLR 
Table 9 Mean Comparisons of SDLR scores among four piloting schools

\begin{tabular}{|c|c|c|c|c|c|c|}
\hline SDLR Latents & School & $M$ & $S D$ & $F$ & $p$ & Post hoc \\
\hline \multirow[t]{4}{*}{ Total } & A & 191.82 & 34.66 & 30.96 & 0.000 & $\mathrm{~F}>\mathrm{D}$ \\
\hline & $\mathrm{C}$ & 197.83 & 34.56 & & & $\mathrm{~F}>\mathrm{C}>\mathrm{A}$ \\
\hline & $\mathrm{D}$ & 193.81 & 33.40 & & & \\
\hline & $\mathrm{F}$ & 204.49 & 33.52 & & & \\
\hline \multirow[t]{4}{*}{ TR } & A & 3.57 & 0.62 & 5.19 & 0.001 & $\mathrm{~F}>\mathrm{C}$ \\
\hline & $\mathrm{C}$ & 3.59 & 0.64 & & & \\
\hline & $\mathrm{D}$ & 3.64 & 0.67 & & & \\
\hline & $\mathrm{F}$ & 3.65 & 0.63 & & & \\
\hline \multirow[t]{4}{*}{$\mathrm{SC}$} & A & 2.95 & 0.79 & 25.15 & 0.000 & $\mathrm{~F}>\mathrm{C}>\mathrm{A}$ \\
\hline & $\mathrm{C}$ & 3.17 & 0.78 & & & \\
\hline & $\mathrm{D}$ & 3.12 & 0.82 & & & \\
\hline & $\mathrm{F}$ & 3.26 & 0.75 & & & \\
\hline \multirow[t]{4}{*}{ IL } & A & 3.23 & 0.90 & 13.15 & 0.000 & $\mathrm{~F}>\mathrm{C}=\mathrm{A}$ \\
\hline & $\mathrm{C}$ & 3.35 & 0.87 & & & \\
\hline & $\mathrm{D}$ & 3.30 & 0.94 & & & \\
\hline & $\mathrm{F}$ & 3.45 & 0.84 & & & \\
\hline \multirow[t]{4}{*}{$\mathrm{AR}$} & A & 3.68 & 1.07 & 26.82 & 0.000 & $\mathrm{~F}>\mathrm{C}$ \\
\hline & $\mathrm{C}$ & 3.75 & 1.04 & & & $\mathrm{~F}>\mathrm{A}$ \\
\hline & $\mathrm{D}$ & 3.60 & 1.04 & & & $\mathrm{~F}>\mathrm{D}$ \\
\hline & $\mathrm{F}$ & 3.95 & 0.95 & & & \\
\hline \multirow[t]{4}{*}{ LL } & $\mathrm{A}$ & 3.17 & 0.80 & 36.47 & 0.000 & $\mathrm{~F}>\mathrm{D}$ \\
\hline & $\mathrm{C}$ & 3.30 & 0.82 & & & $\mathrm{~F}>\mathrm{C}>\mathrm{A}$ \\
\hline & $\mathrm{D}$ & 3.17 & 0.73 & & & \\
\hline & $\mathrm{F}$ & 3.48 & 0.79 & & & \\
\hline \multirow[t]{4}{*}{ CT } & $\mathrm{A}$ & 3.31 & 0.83 & 19.56 & 0.000 & $\mathrm{~F}>\mathrm{C}$ \\
\hline & $\mathrm{C}$ & 3.37 & 0.85 & & & $\mathrm{~F}>\mathrm{A}$ \\
\hline & $\mathrm{D}$ & 3.24 & 0.86 & & & $F>D$ \\
\hline & $\mathrm{F}$ & 3.51 & 0.80 & & & \\
\hline \multirow[t]{4}{*}{ VL } & A & 3.19 & 0.79 & 15.46 & 0.000 & $\mathrm{~F}>\mathrm{C}$ \\
\hline & $\mathrm{C}$ & 3.24 & 0.79 & & & $\mathrm{~F}>\mathrm{A}$ \\
\hline & $\mathrm{D}$ & 3.13 & 0.73 & & & $F>D$ \\
\hline & $\mathrm{F}$ & 3.35 & 0.77 & & & \\
\hline \multirow[t]{4}{*}{ SU } & A & 3.57 & 0.76 & 20.29 & 0.000 & $\mathrm{~F}>\mathrm{D}$ \\
\hline & $\mathrm{C}$ & 3.69 & 0.71 & & & $\mathrm{~F}>\mathrm{C}>\mathrm{A}$ \\
\hline & $\mathrm{D}$ & 3.59 & 0.73 & & & \\
\hline & $\mathrm{F}$ & 3.79 & 0.68 & & & \\
\hline
\end{tabular}

School A $(n=536), \mathrm{C}(n=2,497), \mathrm{D}(n=283), \mathrm{F}(n=2,452)$

city girls in control groups; Cluster 3: low SDLR city boys; Cluster 4: high SDLR boys, who also benefited from nCG). Cluster 1 students may have been overwhelmed because they needed to take both the traditional courses and SDL piloting courses at the same time; Cluster 3 boys obtained very low SDLR scores. Given these findings, students in Clusters 1 and 3 may need special attention from both research and educational leadership.

\section{Demographic context has impact, but can be altered by proper curriculum.}

Opportunities for improving SDLR can exist in varying learning situations, and learners can develop skills and attitudes that are supportive of SDLR. The design of the learning environment should be supportive to lifelong and self-directed learners (Dumont \& Istance, 2010). This finding provides tentative evidence of location, gender, urbanization, and educational level differences on the 
association with SDL. Learner contexts affect personal traits such as grit and autonomy (Mendez, 2015). For example, learners from Western cultures may value student-centered learning and are more likely to be self-directed learners (Aldridge \& Fraser, 2000). An extensive review (Duckworth et al., 2009) also supported the notion that female learners may present better learning readiness in self-regulation, as well as finding that resource-disadvantaged students were less likely to use self-regulatory strategies in learning. However, the implementation of both nCG and the pilot programs could still improve SDLR. Our sample demonstrates that rural students (School F) performed equally well compared to students in other metro schools. This finding echoes Duckworth et al.'s review: resource-disadvantaged students could develop SDL comparable to middle- and high-income students (p. 23).

Interestingly, our sample revealed that senior highschool students had higher SDLR scores, while other studies revealed that SDLR decreases with advancing educational levels (Kell, 2006; Premkumar et al., 2014). We suspect that the inconsistent findings may be due to age or school level being an unreliable factor to students' SDLR. The length of exposure in either traditional or SDL curriculum might be a better predictor of SDLR.

\section{Developing some SDL latent traits in high-school students takes more time}

Developing some of the SDL competencies may take time. From this study's findings, progressive improvement in pilot groups was seen (1E, 2E, and $3 \mathrm{E}$ ) regarding SC, IL, $\mathrm{LL}, \mathrm{CT}$, and VL, while in control groups $(2 \mathrm{C}$ and $3 \mathrm{C})$ only VL had improved after one semester of nCG implementation. When we evaluated only junior- and senior-high data, junior-high students had three latent variables (SC, AR, SU) higher than control groups in Cohort 1, and had six latent variables plus total scores higher than the control group in Cohort 3. Since control group students had only one semester of exposure (i.e., Cohorts 2 to 3 ) to nCG, the improvements were minimal. On the contrary, for the experimental group students who experienced SDL courses for two semesters (i.e., Cohorts 1, 2, and then 3), the improvements became significant. One possible reason is that instructors needed time to redevelop and incorporate self-direction in classroom learning. A Dutch SDL secondary classroom study (Bolhuis \& Voeten, 2001) also highlighted SDL activating features of teaching in the study: where the mere transmission of knowledge occurred in classroom, process-oriented teaching occurred occasionally. Given that entering prestigious colleges is still very competitive in Taiwan, surviving SDL courses can be possible, but challenging, under the mainstream, measurement-driven instruction.

\section{Differentiating Practices of SDL curriculum matters}

Experiences in SDL are affected by the objective, planning, organization, and implementation of a curriculum proposal (Sibthorp et al., 2008). Decades of theoretical and empirical research into self-directed learning or self-regulated learning has demonstrated higher self-awareness, more interests, less anxiety, and better academic performance in students when teachers are learning designers who create supportive environments for active learning (Black \& Deci, 2000). Within this extensive body of literature, however, prescriptive instructional interventions that facilitate particular processes of self-direction or self-regulation have been largely overlooked (Heritage et al., 2009). The only notable exception to this trend is the work of project-based learning, which not only immerses students in real-world context to tackle problems, but also promotes SDL (Walsh, 2010). There exists a need for research on how interventions might tailor SDLR beyond childhood (Duckworth et al., 2009). Although the author of SDLRS recommended that "the overall score is by far the most interpretable measure and the one that should be used" (Guglielmino, 2000, p.1) because the eight latent variables were highly correlated (West \& Bentley, 1990), exploring differences among SDLR latent variables against interventions provides additional clues about how different instructions work toward specific dimensions of SDL. In our study, we witnessed that four piloting programs in Schools A, C, D, and F had their own foci and advantages to improve students' SDLR. Moreover, providing aligned learning strategies transforms students into better self-directed learners (Pilling-Cormick, 1997). Programs in Schools A and C focused on acquiring learning strategies, and student improvement in TR, SC, and SU were obvious. This observation points to the need to assess more realistically the contributions of classroom instructions towards SDLR.

\section{Conclusions}

This research highlights the importance of the curriculum reform context in affecting the way that students' SDL can be developed. To summarize, we used cohort study as a lens to probe how Taiwan high-school students' SDL emerges during the transition of nCG. These results provided evidence supporting our explanations for the positive, though small, effect of implementing nCG in developing self-directed, high-school learners. First, we conclude that many high-school students benefited from curriculum reform. When students actively enacted strategies and constructed process of learning (Zimmerman \& Schunk, 2011) in these SDL programs, their SDLRs were improved (cf., Guglielmino, 2013). Second, the 
progression of SDLR appeared differently among schools. Third, there existed demographic associations with SDLR, and the scores may be lower with some demographic combinations. However, lower SDLR scores may simply reflect that students have learned consistently under environments of directed instruction (Guglielmino \& Associates, 2010), or preferred structured learning options such as lecture and traditional classroom settings (Chen et al., 2020).

\section{Contributions}

Our study offers theoretical, methodological, and practical contributions and contributes to the scholarly discussion about SDLR in high schools. Theoretically, we advance understanding of SDLR in high-school students, and how their SDLR changes over time. The answers to RQ1-1 and RQ1-2 yield the performance and typology of Taiwanese high school students' SDLR, and a significant, but minor effect between learners' backgrounds and SDLR. Moreover, RQ1-3 identified the positive improvement of SDLR under the implementation of nCG. Methodologically, we were able to conduct multiple comparisons by leveraging pilot/non-pilot SDL programs and pre-/post- nCG implementations. SDL cross-sectional surveys provide static snapshots for given populations, but fail to reveal casual relationships that affect the development of SDL (Duckworth et al., 2009; Núñez et al., 2013). Besides, international assessments of educational achievement may include self-regulated learning as a focus in some of the evaluation cycles (e.g., 2000 Programme for International Student Assessment [see Moskowitz \& Stephens, 2004]), but regular surveys of SDLR at large level seem scarce. Our design enabled seeing differences of $\mathrm{nCG}$ in SDLR both concurrently and chronologically. Practically, we advance understanding of SDL practices derived from schools and evaluating what works the best in given SDLR latent variables. The answers to RQ2-1 and RQ2-2 indicate that not only $\mathrm{nCG}$ improves SDLR as a whole; different $\mathrm{nCG}$ instructions in schools influence the composition of students SDLR.

\section{Limitations and Future Research}

The findings in our study are subject to some limitations due to the nature of the data and choice of analyses. First, some advanced statistical techniques (e.g., Difference-indifferences and ANCOVA) were not conducted, given that randomization for treatments or subject matching based on propensity scores was impossible in school settings. Aside from previous studies conducted with classroom experiments (e.g., Black \& Deci, 2000; Camahalan, 2006; Kasworm, 1983; Kocaman et al., 2009), this is, to our knowledge, the first large-scale study of SDL in high school students. Second, the research necessitated a more balanced sample structure that would represent senior highschool and middle-school Taiwanese students on the change of SDLR. Third, regardless of school locations, urbanizations, or gender, or in traditional learning settings (i.e., controls), some students are better able than others to learn self-directly under less advantaged situations. Given that self-efficacy is another critical pillar in developing SDL (Duckworth et al., 2009), future researchers may include items about self-efficacy to grasp how mental strength facilitates the advancement in SDLR. Fourth, we believe another critical variable affecting students' SDLR is teachers. To contextualize the results of studies such as the one reported here, there is now a need to qualitatively explore why specific SDLR latent variables were changed in different piloting programs. Another need would be to distinguish clearly, preferably in quantitative terms, the relationship between academic achievement and SDLR, as it is one of the key goals that the nCG wants to accomplish. Finally, research shows that self-direction and self-regulation are keys to the success of online learning (Kizilcec et al., 2017). To mitigate the negative impact of learning loss due to the COVID-19 school closure, schools are rushing to support educators teaching at a distance (DeMatthews et al., 2020; Kuhfeld et al., 2020). Then again, an SDL-based curriculum reform will properly prepare students to learn in a fast-changing, challenging, and uncertain setting. With the implementation of $\mathrm{nCG}$, schools were able to initiate home-based learning drills with better self-directed learning during the winter break in case a school closure happened (Chen, 2020). A longitudinal research design (e.g., panel survey) would serve further to contribute to the rich understanding of the effects of students' SDL during a pandemic.

Authors Contributions Conceptualization: CC; Methodology: KC; Analysis and investigation: $\mathrm{CC}, \mathrm{KC}$; Writing-original draft preparation: $\mathrm{KC}$; Writing-review, and editing: $\mathrm{CC}$ and HT; Funding acquisition: $\mathrm{CC}$ and $\mathrm{KC}$ and $\mathrm{HT}$.

Funding This work was supported by Taiwan's National Academy of Educational Research under Grant numbers [NAER-103-48-A-102-1-08] and [NAER-107-22-A-1-02-02-6-06], and National Chiao Tung University's Higher Education Sprout Project under Grant number 109W205. The funding agencies had no involvement in this research.

Data Availability All data generated or analyzed during this study are not publicly available due to the restriction of vulnerable research participants by the Research Ethic Committee of National Taiwan Normal University (NTNUREC-201809ES001). 


\section{Declarations}

Conflicts of Interest No potential conflict of interest was reported by the authors.

\section{References}

Aldridge, J. M., \& Fraser, B. J. (2000). A cross-cultural study of classroom learning environments in Australia and Taiwan. Learning Environments Research, 3(2), 101-134

Alonso-Mencía, M. E., Alario-Hoyos, A., Maldonado-Mahauad, J., Estévez-Ayres, I., Pérez-Sanagustín, M., \& Kloos, C. D. (2020). Self-regulated learning in MOOCs: Lessons learned from a literature review. Educational Review, 72, 319-345

Amey, B. E. (2008). An exploration of the relationship between experiential learning and self-directed learning readiness. Doctoral dissertation, Florida Atlantic University.

Bandura, A. (1977). Self-efficacy: Toward a unifying theory of behavioral change. Psychological Review, 84, 191-215

Bandura, A. (1986). Social foundations of thought: A social cognitive perspective. Prentice Hall.

Benson, P. (2001). Teaching and researching autonomy in language learning. Longman.

Black, A. E., \& Deci, E. L. (2000). The effects of instructors' autonomy support and students' autonomous motivation on learning organic chemistry: A self-determination theory perspective. Science Education, 84, 740-756

Bolhuis, S., \& Voeten, M. J. M. (2001). Toward self-directed learning in secondary schools: What do teachers do? Teaching and Teacher Education, 17, 837-855

Brockett, R. G. (1985). The relationship between self-directed learning readiness and life satisfaction among older adults. Adult Education Quarterly, 35(4), 210-219

Butler, D. L., \& Winne, P. H. (1995). Feedback and self-regulated learning: A theoretical synthesis. Review of Educational Research, 65, 245-281

Camahalan, F. M. G. (2006). Effects of self-regulated learning on mathematics achievement of selected Southeast Asian children. Journal of Instructional Psychology, 33(3), 194-205

Chen, K. -Z. (2020). Coaching college students' self-regulated online learning skills. Change the Magazine of Higher Learning, 52(6), $48-56$

Chen, K. -Z., Chen, C. -H., Tsai, H. -F., Li, S. -C., \& Guglielmino, L. M. (2020). Preparation to assess students during implementation of the new Taiwanese k-12 curriculum. International Journal of Self-Directed Learning, 17(2), 10-32.

Cynthia, L. S. (2015). The future of learning: What kind of learning for the 21st century? Paris, France: UNESCO Education Research and Foresight. ERF Working Papers Series, No. 14.

Daniels, E. B. (2011). The impact of an educational intervention on self-directed learning readiness and behaviors in undergraduate nursing students. Doctoral dissertation, Capella University.

Deci, E. L., \& Ryan, R. M. (2000). The "what" and "why" of goal pursuits: Human needs and the self-determination of behavior. Psychological Inquiry, 11(4), 227-268

Deci, E. L., Vallerand, R. J., Pelletier, L. G., \& Ryan, R. M. (1991). Motivation and education: The self-determination perspective. Educational Psychologist, 26, 325-346

De Matthews, D., Knight, D., Reyes, P., Benedict, A., \& Callahan, R. (2020). From the field: Educational research during a pandemic. Educational Researcher, 49, 398-402

Dickinson, L. (1995). Autonomy and motivation: A literature review. System, 23(2), 165-174
Duckworth, K., Ackerman, R., MacGregor, A., Salter, E., \& Vorhaus. J. (2009). Self-regulated learning: A literature review. London, U.K.: Centre for Research on the Wider Benefits of Learning, Institute of Education, University of London.

Dumont, H., \& Istance, D. (2010). Analysing and designing learning environments for the 21st century. In D. Hanna, I. David, \& B. Francisco (Eds.), The nature of learning: Using research to inspire practice. (pp. 19-34). Paris, France: OECD Publishing. https://doi.org/10.1787/9789264086487-3-en

Dweck, C. S. (2006). Mindset: The new psychology of success. New York, NY: Random House.

Dynan, L., Cate, T., \& Rhee, K. (2008). The impact of learning structure on students' readiness for self-directed learning. Journal of Education for Business, 84(2), 96-100

Finestone, P. M. (1984). A construct validation of the self-directed learning readiness scale with labour education participants. Dissertation Abstracts International, 46(5), 1160-1161A

Fiorella, L., \& Mayer, R. E. (2015). Learning as a generative activity: Eight learning strategies that promote understanding. New York, NY: Cambridge University Press.

Guglielmino, L. M. (1989). Guglielmino responds to field's investigation. Adult Education Quarterly, 39, 235-240

Guglielmino, L. M. (2000). Factor loadings: self-directed learning readiness scale (learning preference assessment). Unpublished instrument manual.

Guglielmino \& Associates (2010). What is the self-directed learning readiness scale? Retrieved from https://lpasdlrs.com

Guglielmino, L. M. (2013). The case for promoting self-directed learning in formal educational institutions. SA-eDUC Journal, $10,1-18$

Hacker, D. J., Dunlosky, J., \& Graesser, A. C. (Eds.). (1998). Metacognition in educational theory and practice. Erlbaum.

Heritage, M., Kim, J., Vendlinski, T., \& Herman, J. (2009). From evidence to action: A seamless process in formative assessment? Educational Measurement Issues and Practice, 28(3), 24-31

Hung, D., Huang, J. S., \& Tan, C. (2020). Leadership in times of pandemics: Reflections from Singapore. International Studies in Educational Administration, 48(2), 56-63

Hui, S. K. F., Cheung, H. Y., \& Kennedy, K. J. (2020). A critical review of the development of generic learning outcomes: How engaging is the New Senior Secondary (NSS) Curriculum Reform in Hong Kong? Journal of Education and Human Development, 9(4), 67-84

Karatas, K., \& Zeybek, G. (2020). The role of the academic field in the relationship between self-directed learning and 21st century skills. Bulletin of Education and Research, 42(2), 33-52

Kasworm, C. (1983). An examination of self-directed learning as an instructional strategy. Innovative Higher Education, 8, 45-54

Kell, C. (2006). Undergraduates' learning profile development: What is happening to the men? Medical Teacher, 28, 16-24

Kizilcec, R. F., Pérez-Sanagustín, M., \& Maldonado, J. J. (2017). Self-regulated learning strategies predict learner behavior and goal attainment in Massive Open Online Courses. Computers \& Education, 104, 18-33

Kocaman, G., Dicle, A., \& Ugur, A. (2009). A longitudinal analysis of the self-directed learning readiness level of nursing students enrolled in a problem-based curriculum. Journal of Nursing Education, 48, 286-290

Kuhfeld, M., Soland, J., Tarasawa, B., Johnson, A., Ruzek, E., \& Liu, J. (2020). Projecting the potential impact of COVID-19 school closures on academic achievement. Educational Researcher, 49, $549-565$

Litzinger, T., Wise, J., \& Lee, S. (2005). Self-directed learning readiness among engineering undergraduate students. Journal of Engineering Education, 94, 215-221 
Lodico, M. G., Ghatala, E. S., Levin, J. R., Pressley, M., \& Bell, J. A. (1983). The effects of strategy-monitoring training on children's selection of effective strategies. Journal of Experimental Child Psychology, 35, 263-277

Mahlaba, S. C. (2020). Reasons why self-directed learning is important in South African during the COVID-19 pandemic. South African Journal of Higher Education, 34, 120-136

Mendez, I. (2015). The effect of the intergenerational transmission of noncognitive skills on student performance. Economics of Education Review, 46, 78-97

Moskowitz, J. H., \& Stephens, M. (2004). Comparing learning outcomes: International assessment and education policy. New York, NY: Routledge.

National Academy for Educational Research. (2018). Curriculum guidelines for 12-year basic education: General guidelines [English version]. Taipei, Taiwan: Ministry of Education.

Nordin, N., Abd Halim, N., \& Malik, M. (2016). Assessing readiness for self-directed learning among college students in the provision of higher learning institution. Environment Behaviour Proceedings Journal, 1(3), 91-101

Núñez, J. C., Rosário, P., Vallejo, G., \& González-Pienda, J. A. (2013). A longitudinal assessment of the effectiveness of a school-based mentoring program in middle school. Contemporary Educational Psychology, 38, 11-21

Organization for Economic Co-operation and Development. (2018). The future of education and skills-Education, 2030. Retrieved from

http://www.oecd.org/education/2030/ E2030\%20Position\%20Paper\%20(05.04.2018).pdf

Pan, H. L. W., \& Nyeu, F. Y. (2019). Changing practices of school leadership in Taiwan: Evolving education reforms. In S. Hairon \& J. Goh (Eds.), Perspectives on School Leadership in Asia Pacific Contexts. (pp. 47-60). Berlin: Springer.

Panadero, E., Andrade, H., \& Brookhart, S. (2018). Fusing selfregulated learning and formative assessment: A roadmap of where we are, how we got here, and where we are going. The Australian Association for Research in Education, 45(1), 13-31

Paris, S. G., Byrnes, J. P., \& Paris, A. H. (2001). Constructing theories, identities, and actions of self-regulated learners. In B. J. Zimmerman \& D. H. Schunk (Eds.), Self-regulated learning and academic achievement: Theoretical perspectives.Mahwah: Lawrence Erlbaum.

Pilling-Cormick, J. (1997). Transformative and self-directed learning in practice. In P. Cranton (Ed.), Transformative learning in action: Insight from practice. San Francisco, CA: Jossey-Bass.

Pintrich, P. R. (2004). A conceptual framework for assessing motivation and self-regulation learning in college students. Educational Psychology Review, 16(4), 385-407

Posner, F. G. (1991). Self-directed learning: The missing ingredient for school reform. Changing Schools, 19(1), 1-4

Premkumar, K., Pahwa, P., Banerjee, A., Baptiste, K., Bhatt, H., \& Lim, H. J. (2014). Changes in self-directed learning readiness in dental students: A mixed-methods study. Journal of Dental Education, 78, 934-943

Reimers, F. M., \& Schleicher, A. (2020). A framework to guide an education response to the COVID-19 Pandemic of 2020. Retrieved

from https://globaled.gse.harvard.edu/files/geii/files/ framework_guide_v2.pdf

Schunk, D. H., \& Rice, J. M. (1987). Enhancing comprehension skill and self-efficacy with strategy value information. Journal of Reading Behavior, 19, 285-302
Schunk, D. H., \& Rice, J. M. (1989). Learning goals and children's reading comprehension. Journal of Reading Behavior, 21, 279-293

Schunk, D. H., \& Rice, J. M. (1991). Learning goals and progress feedback during reading comprehension instruction. Journal of Reading Behavior, 23, 351-364

Sibthorp, J., Paisley, K., Gookin, J., \& Furman, N. (2008). The pedagogic value of student autonomy in adventure education. Journal of Experiential Education, 31(2), 136-151

Slater, C. E., Cusick, A., \& Louie, J. C. Y. (2017). Explaining variance in self-directed learning readiness of first year students in health professional programs. BMC Medical Education, 17, 207

Steffens, K. (2015). Competences, learning theories and MOOCs: Recent developments in lifelong learning. European Journal of Education, 50, 41-59

Turner, J. C., Midgley, C., Meyer, D. K., Gheen, M., Anderman, E. M., Kang, Y., \& Patrick, H. (2002). The classroom environment and students' reports of avoidance strategies in mathematics: A multimethod study. Journal of Educational Psychology, 94(1), 88-106

Vallerand, R. J., Fortier, M. S., \& Guay, F. (1997). Self-determination and persistence in a real-life setting: Toward a motivational model of high school dropout. Journal of Personality and Social Psychology, 72, 1161-1176

Walsh, K. (2010). Motivating students to read through project-based learning (Unpublished master thesis). Rochester, New York: St. John Fisher College.

West, R. F., \& Bentley, E. L., Jr. (1990). Structural analysis of the Self-Directed Learning Readiness Scale: A confirmatory factor analysis using LISREL modeling. In H. B. Long \& Associates (Eds.), Advances in research and practice in self-directed learning. (pp. 157-180). Norman, OK: Oklahoma Research Center for Continuing Professional and Higher Education.

Wiley, K. (1981). Effects of a self-directed learning project and preference for structure on self-directed learning readiness of baccalaureate nursing students. Doctoral dissertation, Northern Illinois University. Dissertation Abstracts International, 43(1A).

Wiliam, D. (2018). Embedded formative assessment. (2nd ed.). Bloomington, IN: Solution Tree.

Zhu, M., Bonk, C. J., \& Doo, M. Y. (2020). Self-directed learning in MOOCs: Exploring the relationships among motivation, selfmonitoring, and self-management. Educational Technology Research and Development, 68, 2073-2093

Zimmerman, B. J., \& Schunk, D. H. (2011). Handbook of selfregulation of learning and performance. New York, NY: Routledge.

Zimmerman, B. J., Schunk, D. H., \& DiBenedetto, M. K. (2015). A personal agency view of self-regulated learning: The role of goal setting. In F. Guay, H. Marsh, D. McInerney, \& R. G. Craven (Eds.), Self-concept, motivation, and identity: Underpinning success with research and practices. (pp. 83-114). Charlotte, NC: Information Age Publishing.

Zimmerman, B. J., Schunk, D. H., \& DiBenedetto, M. K. (2017). The role of self-efficacy and related beliefs in self-regulation of learning and performance. In A. J. Elliot, C. S. Dweck, \& S. Yeager (Eds.), Handbook of competence and motivation: Theory and application. (2nd ed., pp. 313-333). New York, NY: Guildford Press.

Publisher's Note Springer Nature remains neutral with regard to jurisdictional claims in published maps and institutional affiliations. 